\title{
Tres Tristes Tigres: El Vasto Fragmento
}

En el cuento "Tlön, Uqbar, Orbis Tertius," 'Borges se describe a sí mismo en el momento en que encuentra el onceno tomo de "A First Encyclopaedia of Tlön" :

Hacía dos afios que yo había descubierto en un tomo de cierta enciclopedia pirática una somera descripción de un falso pais; ahora me deparaba el azar algo más precioso y más arduo. Ahora tenía en las manos un vasto fragmento metódico de la historia total de un planeta desconocido. . .

Aquí Borges nos presenta un texto, el fragmento de un texto, una enciclopedia-que es un resumen, una versión, de la ciencia humana-y nos inunda con una avalancha de meditaciones sobre la relación entre fragmentos y totalidades, entre sinécdoques y metáforas, y también entre sinécdoques que son metáforas. Es decir, el falso artículo enciclopédico, encontrado antes del tomo de la enciclopedia, trataba de la región de Uqbar, y alli Borges y Bioy Casares leyeron que "la literatura de Uqbar era de carácter fantástico y que sus epopeyas y sus leyendas no se referian jamás a la realidad, sino a las dos regiones imaginarias de Mlejnas y de Tlön. ..(p. 14). Dentro de una ficción surgen otras ficciones, mentiras tan verosímiles que, según el cuento, desplazan a la realidad cotidiana hasta el punto de transformarse en la realidad.

En el primer pasaje citado, Borges se refiere al artículo enciclopédico como "una somera descripción," y luego denomina al tomo de la enciclopedia "un vasto fragmento metódico de la historia total de un planeta desconocido." "Descripción" y "fragmento,", derivadas de este contexto borgiano, son dos palabras que nos ayudarán a formular un método de lectura para Tres tristes tigres $^{2}$ de Guillermo Cabrera Infante, un método que revela la estructura de un texto que podemos definir como un vasto fragmento, como una sinécdoque que es una metáfora.

En otra enciclopedia ${ }^{3}$ - no la que emplea Borges - una que trata sólo de poesía y de poética, la sinécdoque se define como una figura en que "the part is substituted for the

\footnotetext{
1 Jorge Luis Borges, "Tlön, Uqbar, Orbis Tertius," Ficciones (Buenos Aires: Sur, 1944), pp. 17-18.

${ }^{2}$ Guillermo Cabrera Infante, Tres tristes tigres (Barcelona: Seix Barral, 1967). Todas las citas son de esta edición.

3 "Synecdoche," en The Princeton Encyclopedia of Poetry and Poetics, ed. Alex Preminger, Third Printing (Princeton: Princeton Univ. Press, 1965), p. 840.
} 
whole, or sometimes the whole for the part." "Generally-sigue el articulo-any internal relation of entity or concept may be used in synecdochic expression, as species for genus, material for thing made, abstract quality for being possessing it, etc." Kenneth Burke reconoce en la sinécdoque la implicación de que sus términos son equivalentes, como en el antiguo concepto de micro y macrocosmos, donde el individuo recapitula la esencia y la estructura del universo. Es decir, si el fragmento en la relación que forma una sinécdoque puede ser una versión de la totalidad, entonces conociendo la parte se conoce a la totalidad. Si ajustamos estas ideas con lo que dicen Jakobson y Halle de la metáfora en Fundamentals of Language- que el acto de hablar consiste en dos actos, uno de seleccionar elementos y otro de conectarlos, y que el acto de selección es la creación de metáforas o la afirmación de la equivalencia de varios términos-entonces podemos ver la gran importancia que tiene la confusión de sinécdoque y metáfora, no sólo para una lectura de Borges sino para la lectura de cualquier texto que se presenta como fragmentado e incompleto.

Lo que declara Borges, indirectamente en su cuento pero directamente en su prólogo a La invención de Morel de Bioy Casares (1940), es que el arte es metafórico y que todo intento de hacerlo más "realista" (diriamos metonímico) es una violación del arte mismo, de su artificialidad. Para Borges, la técnica de la novela del siglo xix, la novela llamada realista, traiciona al arte porque trata de representar un caos-el mundo real. Según Borges, este intento de copiar "el asiático desorden del mundo real" destruye la organización del arte. Sólo podemos tomar en serio estas ideas hasta cierto punto, porque sabemos que la organización de un texto depende del lector y no exclusivamente del artista, y que un texto metonímico en su forma puede ser metafórico en su significado, como bien lo demuestran textos como El asno de oro, La Nausée o La maison de rendez-vous.

El significado-o mejor los significados-que derivan los lectores de un texto no dependen de la unidad orgánica del texto mismo sino del efecto de la acumulación de incidentes, su juxtaposición, tanto en el texto como en la memoria. Por eso tendríamos que extender lo que dice Joseph Frank ${ }^{5}$ de Joyce-que no se puede leer a Joyce sino releerlo-a casi toda la nueva narrativa latinoamericana. Estos textos son en general aglomeraciones de incidentes en que las relaciones internas no son obvias, y nosotros nos encontramos en una situación en que, a base de lecturas repetidas, forjamos las relaciones, proveemos la unidad ausente. Pero el acto de reconstruir la obra por medio de la memoria repite el acto de la creación literaria: es una descripción, una versión de la cosa observada y no la cosa en sí-queriendo decir con esto que es otra función metafórica-y es una nueva fragmentación de lo que ya es un fragmento (sinécdoque) porque el acto de interpretar necesariamente subordina ciertos elementos a otros o deja afuera lo que no se relaciona con la interpretación.

Nuestras responsibilidades al intentar una interpretación son muy graves, pero lo son más cuando estamos trabajando con un texto de otra cultura. Por eso, quisiera empezar mi interpretación de Tres tristes tigres con la crítica de un crítico, con el ensayo que dedicó John Updike a la traducción de Tres tristes tigres en el New Yorker del 29 de enero de

\footnotetext{
4 Kenneth Burke, "Appendix D, Four Master Tropes," A Grammar of Motives (1945), (Meridian Books: Cleveland, 1962), p. 508.

5 Joseph Frank, "Spatial Form in Modern Literature III, Flaubert and Joyce," (1945), The Widening Gyre (New Brunswick: Rutgers Univ. Press, 1963), p. 19.
} 
$1972{ }^{6}$ Lo hago no para corregir a Updike-tampoco para entablar una polémica tardía-sino para ver como podemos aprovecharnos de sus errores para mejorar nuestras lecturas del mismo texto. Así que vamos a considerar a Updike en el contexto de lo que Paul de Man llama "the rhetoric of blindness" - "la retórica de la ceguera." 7

De Man describe una situación en que los críticos hacen algo que no se proponen hacer al leer un texto:

All these critics seem curiously doomed, doomed to say something quite different from what they meant to say. Their critical stance-Lukács's propheticism, Poulet's belief in the power of an original icogito', Blanchot's claim of metaMallarméan impersonality-is defeated by their own critical results. A penetrating but difficult insight into the nature of literary language ensues. It seems, however that this insight could only be gained because the critics were in the grip of this peculiar blindness: their language could grope toward a certain degree of insight only because their method remained oblivious to the perception of this insight. The insight exists only for a reader in the privileged position of being able to observe the blindness as a phenomenon in its own right-the question of his own blindness being one which he is by definition incompetent to ask-and so being able to distinguish between statement and meaning. (pp. 105-106)

Esta percepción austera produce resultados interesantes leída en conexión con el ensayo de Updike porque nos da un método para identificar lo que se afirma dentro de lo que se propone como una negación.

El título de la reseña de Updike, "Infante Terrible," es un "pun" que combina el nombre del autor con el concepto francés del "enfant terrible." Puede ser también una referencia a Les enfants terribles de Cocteau (lo dudo) o sencillamente una manera cómica de decir que Cabrera Infante es terrible. El tema de la traducción, implícito en el chiste bilinguie, reaparece en el primer párrafo, al principio cuando Updike menciona que Tres tristes tigres traducido al francés ganó un premio y luego cuando declara que "the novel was derivative, that its excitement derived from the translation of the methods of Ulysses into Cuban idiom, and that, restored to Joyce's mother tongue, it shows up as a tired copy." Hay dos elementos interesantes en este párrafo, la noción de que el texto de Cabrera es una copia del Ulises, y una serie de adjetivos: "tedious, static, jejune, selfdelighting."

Dejando de lado por un momento la relación entre Joyce y Cabrera Infante, examinemos los adjetivos. Cuatro adjetivos son mucha invectiva para un libro que no sea más que una copia, y habría que preguntarse por qué Updike insiste tanto. Explica, al final de la reseña, que escritores latinoamericanos como Machado de Assis y Garcia Márquez han producido "adventurously original novels"' (p. 93) y, al parecer, el éxito de ellos, que lo llevó a esperar algo igualmente "bueno" de Cabrera Infante entonces es la causa de la diatriba. Pero no es asi. Los adjetivos nos dirán más, en particular si añadimos unos sinónimos: "tedious"' (tedioso, aburrido), "static" (estático, sin movimiento, quieto), "jejune" (sin interés, insípido), "self-delighting" (egoista, pueril, que no respeta al

6 John Updike, “Infante Terrible," The New Yorker, Jan. 29, 1972, pp. 91-99.

7 Paul de Man, "The Rhetoric of Blindness: Jacques Derrida's Reading of Rousseau," Blindness and Insight (New York: Oxford Univ. Press, 1971). 
público). Un texto que Updike llamaría bueno entonces sería "interesante, dinámico, rico, y divertido." La importancia de este ejercicio es mostrar que Updike no analiza a Tres tristes tigres; lo describe.

La descripción revela más sobre el que describe que sobre èl objeto descrito porque Updike nunca define sus criterios. No explica por qué éstas son las palabras "correctas" y evita este peligro describiendo escenas del texto para dar la ilusión de análisis. Pero este "continuo" de descripciones no lleva a ninguna parte, sólo a más descripción. Por ejemplo, a esta seudo-conclusión: "Three Trapped Tigers offers to do for the Havana of 1958 what Ulysses did for the Dublin of 1904." (p. 91) Parece el resultado de un proceso lógico, de un silogismo. En realidad es el resultado de una descripción en que Updike pretende establecer paralelos entre Tres tristes tigres y Ulises:

wandering itineraries are mapped street by street, minor characters reappear in a studied interweave, a variety of voices abruptly soliloquize, a kind of "Oxen of the Sun" procession of literary parodies is worked on the theme of Trotsky's assassination, an endless "Nighttown" drunkenness episode picks up the deliberate hungover banality of the Eumaeus sequence, and a female interior monologue closes the book. (p. 91)

Innecesario decir que la descripción no coincide con el original, y que cuando Updike señala una diferencia importante entre los dos textos: "Unlike Joyce, however, Cabrera Infante packs most of his pyrotechnics and montage into the novel's first half and winds down into a more natural narrative tone." (p. 91), debia haberse dado cuenta de que su comparación existe sólo en sus palabras y no en los objetos comparados. En realidad sería difícil encontrar dos textos más distintos: Ulises, como su título parece indicar, es una meditación irónica sobre una trama heróica; Tres tristes tigres, como el autor ha indicado, es una versión del Satiricón de Petronio.

Pero esta descripción también está incompleta. Joyce hizo mucho más que parodiar a Homero, y Cabrera Infante, como señala Emir Rodríguez Monegal ${ }^{8}$ en su ensayo sobre Tres tristes tigres, añade muchísimo a lo que nos queda de Petronio. Pero aquí otra vez volvemos a la conclusión falsa a que llega Updike sobre el hecho de que Cabrera hace para la Habana lo que Joyce para Dublín. Se ha notado muchas veces que Joyce transforma a sus lectores en dublinenses arrastrándolos por toda la ciudad. Cabrera Infante no se propone semejante tarea: nos da material suficiente para que nosotros reconstruyamos su versión de la Habana de antes de la revolución, no de la ciudad como era en realidad. El texto no es enciclopédico de la misma manera en que lo es Ulises porque es una colección de notas tomadas por uno de los personajes, un libro de memorias, no una summa. Tres tristes tigres es un vasto fragmento que sugiere (o es) una totalidad perdida, es una metáfora para muchas cosas - un mundo, una técnica literaria - pero no es, ni trata de ser, el sistema metafórico que encontramos en Ulises. Los textos tienen finalidades distintas, y si bien los dos terminan con una voz femenina, esta coincidencia no hace más que subrayar sus diferencias.

Lo que realmente molesta a Updike se revela en una repetición sintomática: cuando

\footnotetext{
${ }^{8}$ Emir Rodriguez Monegal, "Structure and Meanings of Three Trapped Tigers," Latin American Literary Review, Spring, 1973, pp. 19-35.
} 
describe a Tres tristes tigres lo llama estático, y cuando describe a Ulises, dice: " Ulysses, static and claustrophobic enough, is energized throughout by the tactful, evocative prose of a master short-story writer..." (p. 93) La palabra "estático" no tiene ningún significado real en el ensayo de Updike y es más bien una señal o un gesto que un valor semántico. Pero, ¿qué quiere decir cuando aplica el término a los dos libros? Sencillamente que hay algo que no le gusta, algo entonces negativo o malo en los dos. Debemos notar parentéticamente que Updike es tal vez el primer crítico que justifica la lectura de Ulises porque Joyce escribió también Dubliners, inversión grotesca de valores, en que una colección de cuentos sirve de apología para una sátira que cambió toda una literatura.

Quizás Updike se siente inseguro al criticar a Tres tristes tigres porque Cabrera Infante no hace lo que él quisiera. "An American reader, especially now that Cuba is remoter than China, longs for a more anatomical portrait of this Havana that has vanished. In the first pages, such a portrait-a cross-section of corrupted and dissatisfied lives-seems to be promised. A sharp imitation of a night-club m.c.'s bilingual prattle lifts the curtain on some monologues by a kept woman, a movie-struck child, an underpaid printer." (p. 91) Otra vez, el comentario no tiene nada que ver con el texto. Un lector norteamericano puede "anhelar"' cualquier cosa con respeto a Cuba, pero ¿qué tienen que ver los deseos de nadie con el libro de Cabrera Infante-que no fue escrito para un público norteamericano? Es decir, Updike parece querer que el libro sea una novela, una descripción de la escena histórica (la Habana prerevolucionaria) con personajes cuyas vidas se relacionan intimamente con la escena. Pero lo que no ve es que Cabrera Infante asume que sabemos algo del mundo real de la Habana de 1958, y que nos da sólo una faceta de aquel cosmos, la faceta que le interesa a él. Hay un elemento autobiográfico claro en este texto, un elemento revelado en, por ejemplo, Un oficio del siglo $x x$, donde Cabrera escribe un prefacio biográfico para su seudónimo Guillermo Cain. Pasajes de este libro reaparecen en Tres tristes tigres.

El no haberse fijado Updike en el lado autobiográfico es icomprensible (aunque la comparación con Ulises tal vez le hubiera estimulado a buscar un Stephen Dedalus), pero la enumeración distorsionada de las escenas que siguen a la introducción en el cabaret la Tropicana nos hace preguntarnos sobre los escrúpulos de Updike como lector. Omite mencionar un monólogo, omite aclarar que el muchacho loco por el cine es el "autor", Silvestre, omite demasiado. Lo que viene después de la escena del cabaret no sigue un orden cronológico muy apretado. Algunos capitulos se refieren a la niñez de los personajes, otros a su llegada a la Habana. El "hombre que trabaja en una imprenta" es un artista comercial, el "bongosero" Eribó. Etc., etc.

Uno se pregunta también con qué atención leyó Updike el texto después de darse cuenta de que no era lo que había querido. No se fija en la cronologia rota que existe en todo el libro y no se fija en la secuencia titulada Bachata (capitulo XIII) en que Silvestre dice: "Fue entonces, exactamente en ese momento (que no olvidaré jamás y para que sea así, tomé estas notas al llegar a casa) que vi la ampolla en el cristal. No sé si saben, ustedes del otro lado de la página, que el cristal de los autos, el del parabrisas, está formado por dos láminas hialinas de idéntico grosor divididas por una hoja plástica invisible.' (p. 344) Aquí tenemos el libro hablando al lector, explicándose a través de un personaje. Es la materia cruda de Silvestre (como señala Arsenio Cué en la p. 404 cuando le pregunta a Silvestre si 
escribirá su conversación), los pedazos que ha logrado salvar de su vida en la Habana durante cierto período.

Cuando Cortázar en Rayuela hace que su narrador relate la actitud de Morelli hacia la composición, podría muy bien haber estado hablando de Tres tristes tigres:

En alguna parte Morelli procuraba justificar sus incoherencias narrativas, sosteniendo que la vida de los otros, tal como nos llega en la llamada realidad, no es cine sino fotografía, es decir que no podemos aprehender la acción sino tan sólo sus fragmentos eleáticamente recortados. No hay más que los momentos en que estamos con ese otro o cuando él nos cuenta lo que le ha pasado o proyecta ante nosotros lo que tiene que hacer. Al final queda un álbum de fotos, de instantes fijos; jamás el devenir realizándose ante nosotros, el pasado del ayer al hoy, la primera aguja del olvido en el recuerdo. ${ }^{9}$

Este es el concepto de articulación que concibió Cortázar-basado como vemos en una especie de mimesis-una teoría que Cabrera Infante lleva a la práctica.

La intuición a que nos lleva Updike en su ceguera es la imposibilidad de leer (literalmente de leer) - un texto con presupuestos fijos. Aunque es una lección tan trivial que no hay ninguna razón de repetirla-precisamente porque sabemos que no podemos escaparnos de nuestra subjetividad-debemos ajustar nuestra lectura al texto, buscando los signos de orientación que nos da el texto mismo. Updike, sin embargo, nos ha hecho un gran favor: su incapacidad de ver lo que tiene delante, su inhabilidad de trascender un concepto monolítico de lectura, su sensibilidad orientada exclusivamente hacia una novela que ya no existe, son todos avisos que hay que tener en cuenta.

La primera tarea del lector de Tres tristes tigres es la reconstrucción. Debe empezar reconstruyendo el texto, organizando lo que parece una mera aglomeración. Es él quien conecta los fragmentos de la vida de los personajes como si estuviera trabajando con un " "puzzle," conectando las piezas hasta ver una totalidad nebulosa, un fragmento completo que señala una infinidad de posibilidades. Conste que aquí hay más piezas ausentes que presentes.

Tres tristes tigres, como las Memórias póstumas de Brás Cubas de Machado de Assis o La invención de Morel de Bioy Casares es un texto elegíaco. Como la obra lírica temprana de Borges, documenta una pérdida, no sólo del objeto observado sino del observador también. Cabrera Infante, a diferencia, por ejemplo, de Bioy, no se concentra en el concepto de la muerte que precede a una resurrección estética, la obra de arte que surge de las cenizas de la vida, tal vez porque él (como sus personajes) se da cuenta de que los dos mundos, aunque son tangenciales, están eternamente separados. El mundo a que corresponde el texto está muerto, y el texto sólo puede ser una metáfora, una realidad de palabras sin referencia a nada que sea palpable. En Bioy el mundo perdido queda reducido a una nostalgia momentánea, subordinada rápidamente al mundo estético.

La metáfora principal en que se basa Tres tristes tigres es la idea de que la representación estética es una traición. La obra de arte no puede referir a nada sino a sí misma, y, como es una traducción (no olvidemos que en latín metáfora y traducción tienen las mismas raíces etimológicas) de un modo de ser a otro, no puede considerarse superior a

9 Julio Cortázar, Rayuela (Buenos Aires: Sudamericana, 1963), p. 532. 
su propio asunto. La sátira de Cabrera Infante es un estudio de la idea de la traición, como forma y como contenido. Es decir, una clase de traición puede sustituirse por otra: si un traductor llama a los leones de un texto morsas, ha violado una confianza, si un amigo miente a otro amigo, rompe un eslabón, si un texto pretende capturar escenas de varias vidas pero sólo logra dar una versión de aquellas escenas, entonces él también ha roto su promesa al original.

El satírico es, por supuesto, satirizado en la obra de Cabrera Infante. Silvestre el supuesto "secretario de la historia,"' es su propio asunto: tiene que deformar lo que se acuerda de si mismo en el mero acto de transcribirlo. Silvestre es el enemigo implacable del olvido (se refiere a este odio en la p. 287), está muy consciente de la persistencia de la memoria, de la inevitabilidad de la invasión del presente por el pasado (ver p. 306), pero él queda derrotado porque sólo puede dar la cáscara de lo que ve. Como las manzanas que crecen al margen del Mar Muerto, la representación, la metáfora en otras palabras, siempre promete algo, siempre atrae por medio de un exterior hermoso, pero siempre se transforma en cenizas en la boca del que la muerde. Dentro del texto, este vacío, esta esterilidad, se refleja en los juegos de palabras de los personajes.

Los "puns"' son un modo por el cual los personajes producen la apariencia de acción: constituyen un espacio verbal, pero este espacio es ilusorio porque no es más que metáfora, sustitución, y no el fluir de la metonimia. No hay-literalmente-espacio para los personajes porque han llegado a su límite, tanto cultural como histórico. Como el narrador de Bioy en La invención de Morel, ellos se transformarán en arte, pero el precio de la transformación - la muerte-es lo que recibe énfasis aqui. La salvación que postula Bioy para su narrador es un consuelo muy pobre para los personajes de Cabrera Infante porque trae consigo otra traición: tiene que haber un intérprete, un Silvestre o nosotros mismos, los lectores.

El espacio metafórico, que crean los personajes al jugar con palabras, y en que “viven"' después de que redacta Silvestre su versión de lo que ha experimentado, no es en realidad ningún espacio. Por eso los personajes existen sólo cuando están juntos: son todos imágenes gemelas unos de otros, reflejos de reflejos. Vemos esto en la relación entre Arsenio Cué y Silvestre porque los demás personajes los señalan como gemelos (aunque no se parecen físicamente). Constituyen un comentario irónico sobre una observación que ha hecho el profesor J. Hillis Miller sobre los personajes de la novela victoriana: "In most Victorian novels the protagonist comes to know himself and to fulfill himself by way of other people.' 10 Los personajes de Cabrera Infante son sombras que nunca serán completas.

Esta condición de existencia fragmentada se representa en el texto con la muerte de un personaje que nunca aparece. Bustrófedon es un mago lingüístico, un maestro del "pun," y su muerte provoca una crisis en la vida de los otros personajes. Ellos tratan de conservar sus obras (Tà secuencia paródica llamada "La muerte de Trotsky referida por varios escritores cubanos después o antes" es suya) pero como anotan los personajes, su obra no es él. El está perdido para siempre. Y se transforma inmediatemente en personaje dentro de su memoria, y finalmente llega a ser lo que es el destino de todos: palabras. Para el

10 J. Hillis Miller, The Form of Victorian Fiction, Second Printing (Notre Dame: Univ. of Notre Dame Press, 1970), p. 5. 
lector, Bustrófedon no es nada sino lenguaje, y si no lo experimentamos directamente es, a pesar de todo, tan real como Cué o Silvestre. Su ausencia es un signo de la ausencia que está detrás de la existencia de todos los personajes.

Lo que dice Hillis Miller sobre la novela (aunque nunca define ese término ambiguo) puede ser verdad: "A novel is a temporal rhythm made up of the movement of the minds of the narrator and his characters in their dance of approach and withdrawal, love and hate, convergence and divergence, merger and division,"' (p. 6) pero debemos recordar al mismo tiempo que el tiempo narrativo es lingüistico. Cuando termina la narración, termina el texto. E1 libro de Cabrera Infante es, o aspira ser, el lenguaje de un lugar y un tiempo especificos-o por lo menos una versión de aquel lenguaje-y el hecho de que está encerrado en un libro señala que está muerto. Como Cien años de soledad, como La invención de Morel, el texto aquí es una tumba. Para Cabrera Infante, sin embargo, la creación del texto, el monumento verbal a los muertos, es otra traición: ya que no puede ser más que metáfora, el asunto tiene que ser efímero. El texto contiene fantasmas de fantasmas, los restos de un lenguaje, que es a su vez una metáfora.

La disimulación temporal es la ocupación principal de los personajes de Cabrera Infante: ellos están muriendo con su mundo, como dinosauros a borde de la extinción. El lenguaje es la única manera que les queda de disimular su desespero. Como las digresiones e interpolaciones de la novela griega, sus aventuras verbales dan la ilusión de ensanchar el tiempo, pero son sólo decorado. El mundo de Tres tristes tigres es estéril, a menos que se le considere como origen de una obra de arte-de la misma manera en que el mundo de Encolpio y Giton en el Satiricón es un mundo que se revela como sin trascendencia. Transformar el día en noche, recrear las palabras, estar en movimiento perpetuo: éstos son los modos con que los personajes de Cabrera Infante se engañan. No es, naturalmente, más que otra traición, una que lleva a la muerte y a la resurrección estética. Una metáfora es una realidad de palabras, un fragmento de fragmentos; vivir en aquella realidad es suicidarse. 